\title{
Is combined MDCT and echocardiography needed to guarantee accuracy in diagnosis and surgical planning of DORV and associated anomalies?
}

\author{
Samira Saraya ${ }^{1 *}$, Yousra Mahmoud Ahmad², Ragab Hani Donkol ${ }^{1}$, Hazem Hamed Soliman', \\ Reem Ibrahim Ismail ${ }^{3}$, Mahmoud Saraya ${ }^{4}$ and Iman Hamdy Ibrahim ${ }^{1}$
}

\begin{abstract}
Background: The term of Double-outlet right ventricle (DORV) is used to describe a spectrum of complex congenital cardiac malformations where anomalies of the ventriculo-arterial alignment are noted where both great arteries (pulmonary artery and aorta) originate completely or predominantly from the right ventricle. The purpose of this study is to evaluate the diagnostic accuracy of electrocardiography (ECG) gated multidetector computed tomography (MDCT) in preoperative assessment of DORV and its associated malformations, providing key anatomic parameters that affect surgical planning.

Results: A total of 50 patients diagnosed by echocardiography with DORV referred from our institute between September 2018 and August 2020 were enrolled. The location of the ventricular septal defect (VSD) to the great vessels and the alignment of the great vessels to each other as well as other associated malformations that affect the surgical planning were assessed by MDCT. The patients were retrospectively classified into subgroups according to the relative positions of the great arteries, the relationship between the great arteries and the VSD, and the presence of associated malformations according to the classification of Society of Thoracic Surgeons database. The diagnostic value of MDCT and transthoracic echocardiography (TTE) in evaluation of associated cardiac malformations apart from double outlet right ventricle was compared in 20 patients, whom surgeries were performed and surgical results were obtained. Fallot type of DORV was the most common clinical type which represented $48 \%$ of the patients in which the VSD is committed to the aorta. The second most common clinical type was Taussig-Bing anomaly which represented 30\% of the patients and the VSD was seen committed to the pulmonary artery. The atrio-ventricular septal defect (AVSD)/univentricular type represented $16 \%$ of the patients in the current study, with pulmonary and systemic venous anomalies, heterotaxy syndrome and situs anomalies were commonly associated. A total of 53 malformations apart from DORV were found in 20 patients whom performed surgical interventions. MDCT detected different vascular and situs anomalies in those patients with $100 \%$ sensitivity and $100 \%$ positive predictive value compared to $71.4 \%$ and $94 \%$ respectively in TTE. On the other hand, in our study TTE was superior to MDCT for detection of intracardiac anomalies with $100 \%$ sensitivity and $100 \%$ accuracy compared to $87.5 \%$ and $95 \%$ respectively in MDCT.
\end{abstract}

\footnotetext{
${ }^{*}$ Correspondence: semsaraya@yahoo.com

1 Diagnostic and Intervention Radiology Department, Kasr Al-Ainy,

Faculty of Medicine, Cairo University, El-Manial, Cairo 11956, Egypt

Full list of author information is available at the end of the article
} original author(s) and the source, provide a link to the Creative Commons licence, and indicate if changes were made. The images or other third party material in this article are included in the article's Creative Commons licence, unless indicated otherwise in a credit line to the material. If material is not included in the article's Creative Commons licence and your intended use is not permitted by statutory regulation or exceeds the permitted use, you will need to obtain permission directly from the copyright holder. To view a copy of this licence, visit http://creativecommons.org/licenses/by/4.0/. 
Conclusions: Our study suggested that ECG gated MDCT serves as a rapid, noninvasive imaging modality with good spatial resolution and provides excellent diagnostic image quality and has satisfactory diagnostic accuracy in the preoperative assessment of DORV. It is superior to echocardiography in providing a comprehensive mapping of the anatomy of complex anomalies especially that of extra-cardiac structures such as aorta, systemic veins, pulmonary veins, and pulmonary arteries. However, it can miss tiny intracardiac malformations. So combining the results of MDCT and echocardiography would be beneficial to guarantee the accuracy of diagnosis of DORV.

Keywords: Cardiac, MDCT, Double-outlet right ventricle, Ventricular septal defect, Atrio-ventricular septal defect/univentricular, Pulmonary and systemic venous anomalies, Heterotaxy syndrome and situs anomalies

\section{Background}

The term of Double-outlet right ventricle (DORV) is used to describe a spectrum of complex congenital cardiac malformation where anomalies of the ventriculo-arterial alignment are noted [1]. It occurs in approximately 1 in 10,000 live births, and $1 \%$ of children with congenital heart disease. The term DORV was not used until 1957 when A.C. Witham first "coined" it, although that complex congenital cardiac malformation had been described pathologically for many years [2].

In such cases one whole great artery and $50 \%$ or more of the other ( $150 \%$ rule) or both great arteries completely (200\% rule) arise from the RV [3].

Therefore, a ventricular septal defect (VSD) must be present, being the only pathway for the left ventricle (LV) to empty itself [4].

Management as well as prognosis of these cases relies upon proper understanding of the relationship between the great vessels and the VSD. Also, the relation of the great vessels' anatomy to the outlets and the associated malformations are crucial to be properly identified [5].

According to the society of Thoracic Surgeons database, the patients with a DORV are classified into 4 basic types; (a) Fallot type: DORV with subaortic VSD and pulmonary stenosis (PS), (b) VSD type: DORV with doubly committed VSD and no PS, (c) Taussig Bing anomaly: DORV with subpulmonic VSD and D) DORV with remote VSD or atrioventricular septal defect type (AVSD) $[1,6,7]$.

Early diagnosis of those patients with proper early management had played an important role in increasing their survival. So, from the fetal stage onwards, imaging is required through all stages of patient's care as it outlines anatomy and physiology. Also, it helps to select proper management solutions, monitoring different interventions consequences and guiding prognosis and leading to raise the surviving rate into adulthood [8].

Transthoracic echocardiography (TTE) has been regarded as the first-line imaging modality for pediatric patients with DORV. However, the small acoustic window and operator dependence are inherent disadvantages that affect its diagnostic performance [9].
Electrocardiographically (ECG)-gated computed tomography with high temporal resolution, low radiation doses, and excellent image quality has evolved as a reliable tool for assessment of patients with congenital heart diseases such as DORV [10]. MDCT provides a comprehensive mapping of the anatomy of complex anomalies, especially that of extra-cardiac structures such as aorta, systemic veins, pulmonary veins, pulmonary arteries, beyond what is possible with echocardiography and hence is a good complement to echocardiography [11].

\section{Methods}

Fifty patients with double outlet right ventricle referred from radiology department of our institute, in between September 2018 and August 2020 were enrolled. Ethical committee approval of the radiological department of our institute was obtained. Patients diagnosed by echocardiography with double outlet right ventricle in pediatric age group were included in this study. While clinically unstable patients or patients with hypersensitivity to the iodinated contrast and patients with impaired renal function were excluded.

All examinations were performed using a dual source CT scanner (Somatom Definition; Siemens Medical Solutions, Forchheim, Germany). Patient were asked to fast for $2-3 \mathrm{~h}$ in neonates and $4-6 \mathrm{~h}$ in older children. Venous catheters (21-to 24-gauge) were placed. Description of the procedure to the patients' parents with their reassurance was performed. Written informed consent (declaring adverse reactions to the iodinated contrast agent and radiation exposure) was obtained from their parents. A crush cart was prepared with a) Adrenaline ampoule if severe hypotension or severe anaphylaxis occurs, B) Anti-histaminic and cortisone to be used if reaction to contrast occurs. Facility for transferring the patient to the intensive care unit if uncontrolled complication develops was planned and available. Short- term sedation was achieved by ketamine with a dose of $1 \mathrm{mg} / \mathrm{kg}$. Non- diluted, non-ionic contrast material was injected (Omnipaque 300-350; Nycomed Amersham, Princeton, NJ) into an antecubital vein at a rate of $1.2-2.5 \mathrm{ml} / \mathrm{s}$, followed by $20 \mathrm{ml}$ of 


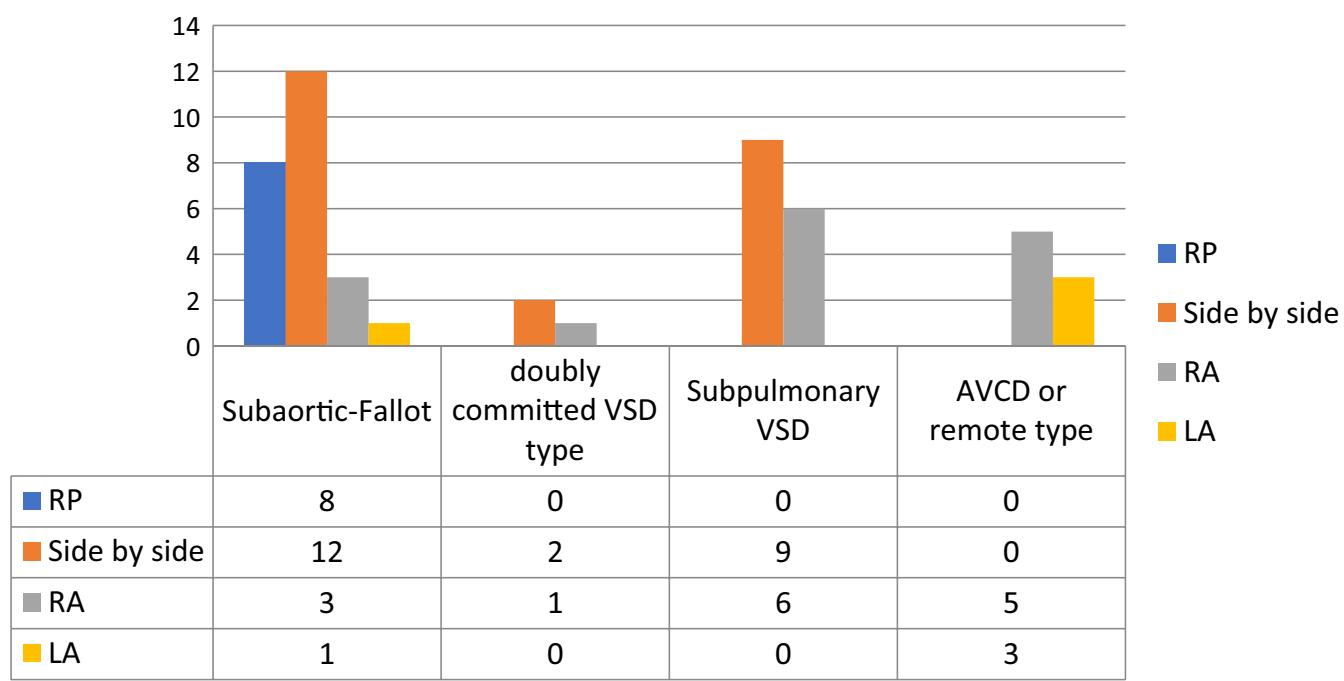

Fig. 1 classification according to the alignment of the great vessels and VSD location. *RP: right posterior position, RA: right anterior position, LA: left anterior position

saline solution. The injected volume was adjusted to the body weight $(1.5 \mathrm{ml} / \mathrm{kg})$.

Scanning was performed using a Prospective ECGtriggering protocol with the following acquisition parameters: Tube voltage, $80 \mathrm{kV}, \mathrm{mAs} 60-100$ at it was adjusted in each case according to body habitus., Gantry rotation time, $0.28 \mathrm{~s}$; and pitch 3.4

Bolus tracking technique was used with a region of interest (ROI) in the proximal descending aorta or at the left ventricle with a pre-defined threshold between 100 and $150 \mathrm{HU}$.

Multi-phase examination of the heart was then performed from the inlet of the thorax to $2 \mathrm{~cm}$ below the diaphragm level. Sequential series of images in the mid venous and mid arterial phases of enhancement to ensure opacification of both sides of the heart and all extra-cardiac vessels. A scan delay of $4 \mathrm{~s}$ was commonly used to evaluate right sided heart structures and a scan delay of $5-8 \mathrm{~s}$ is commonly used to evaluate left sided heart structures. Some patients with complex venous anomalies required additional delayed phase after $30-60 \mathrm{~s}$ according to patient age, size and heart rate.

Axial images are rapidly reconstructed at $1.0 \mathrm{~mm}$ slice thickness and increment of $0.8 \mathrm{~mm}$ and reviewed to ensure satisfactory quality of the images.

The patient is kept $15-30$ min after the procedure under observation till recovery of sedation.

\section{Image reconstruction of post processing}

All acquired data were processed on a workstation (Somatom Definition; Siemens Medical Solutions, Forchheim, Germany). A slice thickness of $0.75 \mathrm{~mm}$ and an increment of $0.7 \mathrm{~mm}$ were chosen for image reconstruction.

The multiplanar reformation (MPR), maximum intensity projection (MIP), and volume rendering (VR) were used for image analysis.

- Multi-planar reformation (MPR)

- Reformation planes are defined by projecting a line on one of the transverse sections so that the resultant MPR images will be perpendicular to the transverse plane and parallel to the projected line.

- MPR were applied to all patients. The variable imaging planes of MPR simultaneously display the pulmonary veins on the same imaging plane and identify the draining sites of the vertical vein to the systemic veins.

- Thin MPR images are used for precise measurements of vessels.

- Curved planar Reformat (CPR)

- CPR images are used to visualize curved vascular structures.

- It was of great value in assessment of the caliber of the thoracic aorta and main pulmonary arteries.

- Volume rendering (VR)

- VR obtained after editing of axial images to remove bone structures and other soft tissues. 
Table 1 Classification of the patients according to their clinical types and VSD location:

\begin{tabular}{lllll}
\hline Type & Type I-Fallot type & Type II- VSD type & $\begin{array}{l}\text { Type III- (Taussig- } \\
\text { Bing anomaly) }\end{array}$ & Type IV-Remote or AVSD type $\begin{array}{c}\text { Total } \\
\text { number of } \\
\text { patients }\end{array}$ \\
\hline Location of VSD & Sub-aortic & Doubly committed & Sub-pulmonic & $\begin{array}{l}\text { VSD away from both pulmonary } \\
\text { artery and aorta }\end{array}$ \\
No. of patients & 24 & 3 & 15 & 8 \\
$\%$ & 48 & 6 & 30 & 16 \\
\hline
\end{tabular}

VSD: Ventricular septal defect, AVSD: atrio-ventricular septal defect

Table 2 Number of associated malformations detected

\begin{tabular}{lll}
\hline Right ventricular outflow obstruction & 24 & $17.7 \%$ \\
Pulmonary artery anomalies & 16 & $11.8 \%$ \\
Pulmonary venous anomalies & 5 & $3.8 \%$ \\
Aortopulmonary collaterals & 4 & $3 \%$ \\
Aortic anomalies & 20 & $14.8 \%$ \\
Systemic venous anomalies & 18 & $13.4 \%$ \\
Atrial septal defects & 12 & $8.8 \%$ \\
Patent ductus arteriosus & 8 & $5.9 \%$ \\
Cardiac apex and position abnormalities, e.g., & 7 & $5.1 \%$ \\
dextrocardia and mesocardia & & \\
Heterotaxy syndrome and situs anomalies & 14 & $10.5 \%$ \\
Mitral atresia & 1 & $0.7 \%$ \\
Coronary artery anomalies & 6 & $4.5 \%$ \\
& 135 & \\
\hline
\end{tabular}

- The VR technique was particularly useful for displaying structures that course parallel or oblique to the transverse plane. It was helpful in the demonstration of the spatial relationship of the extracardiac vessels as well as visualization of the pulmonary and systemic venous drainage.

- Maximum intensity projection (MIP)

- With this technique, CT images are acquired at their routine section thickness and then combined in multiples, or "slabs" to create a thicker image.

- This technique was best used in assessment of relation of the great vessels of the heart and pulmonary vein drainage.

\section{Image analysis}

All images were assessed by at least two cardiac radiologists (each having an experience of 7 years at least in cardiac imaging). The patients were retrospectively classified into subgroups according to the relative positions of the great arteries, the relationship between the great arteries and the VSD according to the classification of Society of Thoracic Surgeons database (1), and the presence of associated malformations.

\section{Assessment of the location of the VSD relative to the arterial valves was performed as follows}

- If VSD was close to the aortic valve, it was termed a subaortic VSD.

- In a similar manner, if VSD was close to the pulmonary valve, it was termed a sub-pulmonary VSD,

- In a subset of patients, the VSD was remote and associated with AVSD.

- In a few patients, the VSD was committed to both semilunar valves and called doubly committed VSD.

\section{Assessment of the alignment of the great vessels}

The alignment of the great vessels was classified as follows:

- If the aorta was posterior and to the right of the main pulmonary artery (MPA), it was termed the right posterior (RP position).

- If two great arteries were side by-side, it was termed the side-by side position.

- If the aorta was anterior and to the right of the MPA, it was termed the right anterior (RA position).

- If the aorta was anterior and to the left of the MPA, it was termed the left anterior (LA position).

Other associated anomalies were also assessed e.g. intra-cardiac anomalies, coronary artery anomalies, anomalies of great vessels, and separate thoracic and abdominal anomalies.

\section{Statistical method}

The collected data were coded, tabulated, and statistically analyzed using IBM SPSS statistics (Statistical Package for Social Sciences) software version 18.0, IBM Corp., Chicago, USA, 2009. 


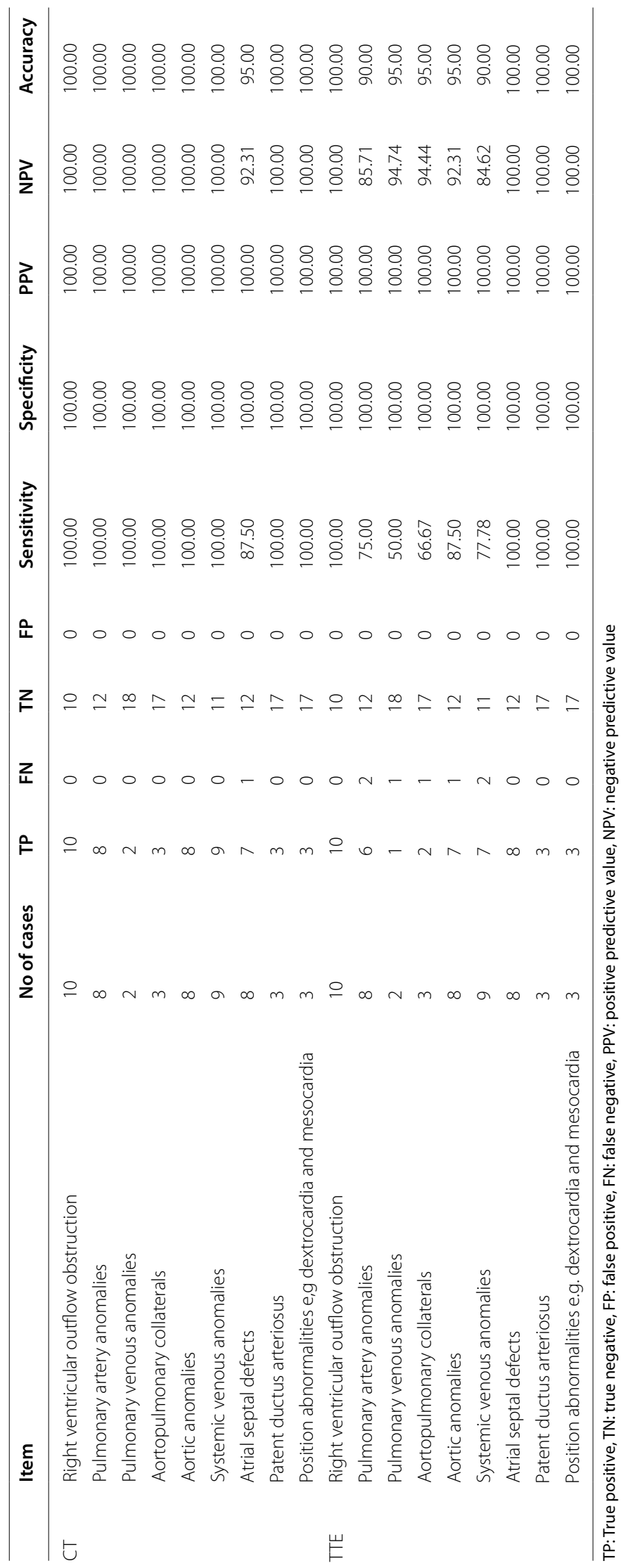


Table 4 The estimated radiation dose in the patient group included in the current study

\begin{tabular}{ll}
\hline CTDlvol (mGy) & $1.33 \pm 0.13$ \\
DLP $(\mathrm{mGy} \times \mathrm{cm})$ & $11.50 \pm 3.71$ \\
Effective dose $(\mathrm{mSv})$ & $0.21 \pm 0.06$ \\
\hline
\end{tabular}

Accuracy was represented using the terms sensitivity, specificity, +ve predictive value, - ve predictive value, and overall accuracy.

\section{Accuracy calculations}

$$
\begin{aligned}
& \text { Sensitivity }=T(+) \text { ve } \div[T(+) \text { ve }+F(-) \text { ve }] \\
& \text { Specificity }=T(-) \text { ve } \div[T(-) \text { ve }+F(+) \text { ve }] \\
& \text { Positive predictive value }=T(+) \text { ve } \div[T(+) \text { ve }+F(+) \text { ve }] \\
& \text { Negative predictive value }=T(-) \text { ve } \div[T(-) \text { ve }+F(-) \text { ve }] \\
& \text { Overall accuracy }=[T(+) \text { ve }+T(-) \text { ve }] \div \text { All sample }
\end{aligned}
$$

\section{Estimation of the radiation dose}

The scan length was documented for every CT examination. The dose length product (DLP) values were recorded as displayed on the $\mathrm{CT}$ console for each $\mathrm{CT}$ scan. The effective dose was calculated from the DLP values and using a conversion coefficient of 0.014 for the pediatric chest. The effective dose $(\mathrm{msV})$ of the patient ranged from ( 0.11 to 0.21$)$ with the mean effective dose was 0.11 .

\section{Results}

This study included 50 patients, 26 males and 24 females with age ranging from 45 days to 11 years. Mean age of the patients was 2.1 years.

Patients were classified according to their clinical types and VSD location as presented in Table 1. While in Fig. 1 they have been classified according to the alignment of the great vessels and VSD location.

Multiple associated malformations have been detected other than DORV, A 135 associated malformations were detected by MDCT angiography classified as detailed in Table 2. Pulmonary artery anomalies (16 patients) included 9 patients with main pulmonary artery stenosis (7\%), 2 patients had right pulmonary atresia $(1.5 \%), 3$ patients showed left pulmonary stenosis $(2.3 \%)$ and 2 patients had left pulmonary artery atre$\operatorname{sia}(1.5 \%)$.
Associated aortic arch anomalies were detected in 20 cases where right sided aortic arch was seen in 13 patients (9.6\%), interrupted aortic arch in 4 patients (3\%) and aortic coarctation in 3 patients $(2.2 \%)$.

Systemic venous anomalies were detected in 18 cases, 7 cases (5.1\%) had persistent left superior vena cava (SVC), 5 cases $(3.7 \%)$ showed double SVC, 5 cases $(3.7 \%)$ had interrupted IVC while 1 case $(0.75 \%)$ with left sided IVC was seen.

Multislice CT angiography detected 7 mal-positions of the heart, 5 cases (3.7\%) with dextrocardia where the heart is located in the right thorax, with the base-apex axis tilted toward the right and 2 cases (1.5\%) with mesocardia where the heart is midline in location.

Fourteen cases with situs abnormalities were confirmed by MDCT angiography; 5 cases (3.7\%) with situs inversus. Nine cases (6.6\%) with situs ambiguous; in which 7 of them showed left isomerism while the other 2 cases showed right isomerism.

The diagnostic value of MDCT and TTE in evaluation of associated cardiac malformations apart from double outlet right ventricle was compared in 20 patients, whom surgeries were performed and surgical results were obtained.

There was a total of 53 associated malformations detected by MDCT confirmed by surgical results. A summary of the findings obtained with MDCT and TTE are shown in Table 3. TTE missed detecting two pulmonary artery anomaly (2/8), one aortopulmonary collateral vessel $(1 / 3)$, one anomalous pulmonary venous connection $(1 / 2)$, one aortic anomaly (1/8), and two systemic venous anomalies (2/9), while MDCT missed detecting only one atrial septal defect (1/8). The sensitivity, specificity, positive predictive value, and negative predictive value of MDCT and TTE for each group are presented in Table 3. MDCT detected the different great vessels and situs anomalies in those patients with $98.6 \%$ sensitivity, $100 \%$ specificity and $99.5 \%$ accuracy, while TTE showed a sensitivity, specificity and accuracy of $84.1 \%, 100 \%$ and $96 \%$ respectively. On the other hand, TTE was superior to MDCT for detection of intracardiac anomalies with $100 \%$ sensitivity and $100 \%$ accuracy compared to $87.5 \%$ and $95 \%$ respectively in MDCT.

The estimated radiation dose in the patient group included in the current study, [CTDIvol (mGy), DLP (mGy $\mathrm{x} \mathrm{cm}$ ), Effective dose $(\mathrm{mSv})]$, were presented in Table 4 (Figs. 2, 3, 4, 5).

(See figure on next page.)

Fig. 2 MDCT showing. $\mathbf{a}$ Oblique and $\mathbf{b}$ axial images showing aorta and pulmonary artery arising from the right ventricle with the aorta seen anterior and to the right of the pulmonary artery (RA position), c oblique image showing infundibular pulmonary stenosis and right ventricular outflow tract obstruction (RVOTO), $\mathbf{d}$ oblique image subaortic VSD with overriding of the aorta, e VR image showing left pulmonary artery stenosis 'arrow' 

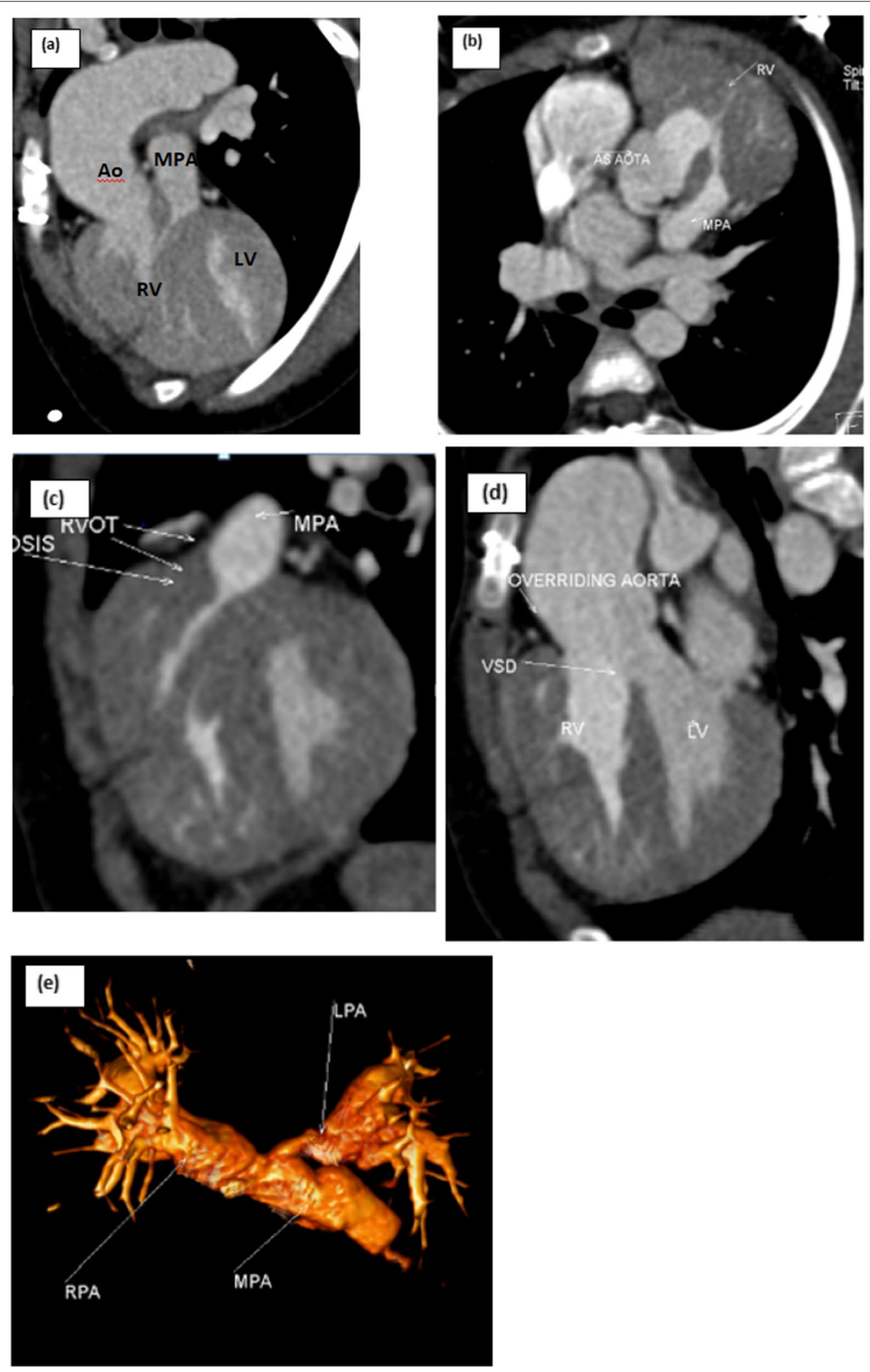

Fig. 2 (See legend on previous page.) 

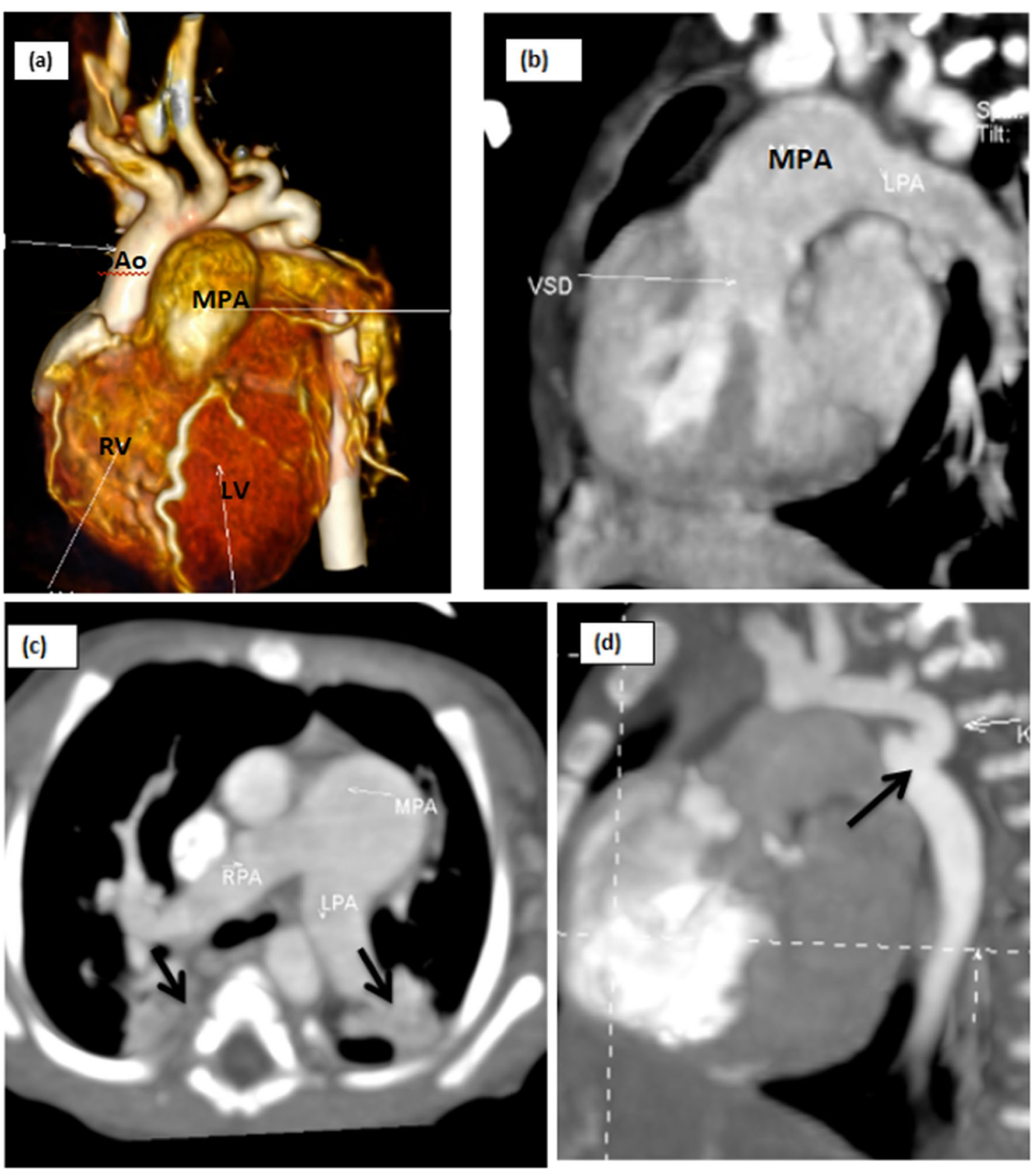

Fig. 3 cardiac CTA showing: a VR image showing aorta and pulmonary artery arising from the right ventricle with dilated main pulmonary artery. $\mathbf{b}$ Sagittal oblique image showing subpulmonic VSD with dilated main pulmonary artery. $\mathbf{c}$ Axial image showing side by side relationship of the aorta (Ao) and main pulmonary artery (MPA) with dilated main pulmonary artery and its central branches. Bilateral basal pulmonary consolidations are also seen (arrows). d Sagittal MIP images show Pseudocoarctation of the aorta "arrow" 

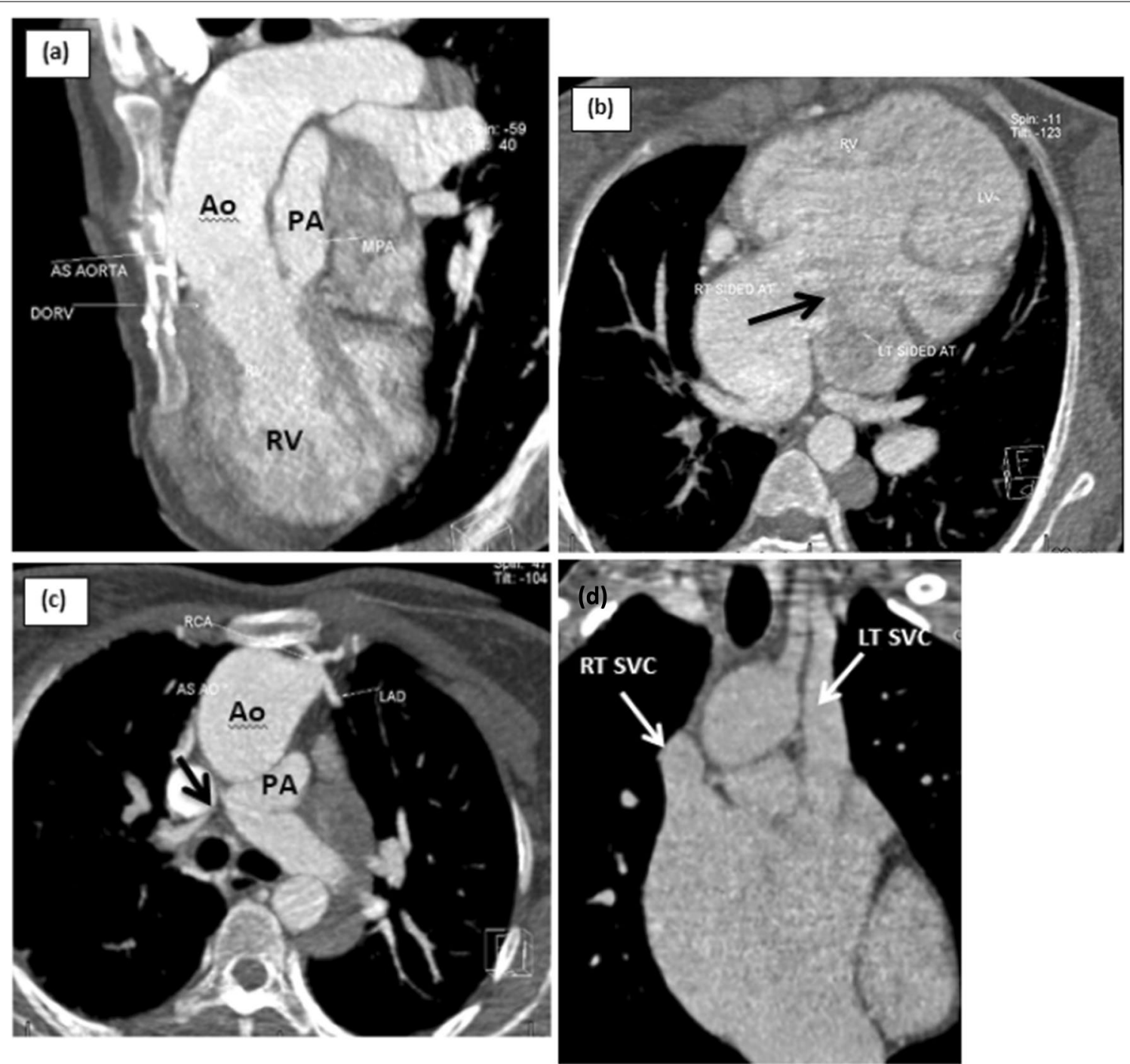

Fig. 4 CCTA showing: a sagittal oblique image showing the aorta and pulmonary artery are seen arising from the dominant right ventricle. b Axial image showing Av canal defect (arrow). c Axial image showing right pulmonary atresia (arrow) and anomalous origin of the coronary arteries as right coronary artery (RCA), left anterior descending artery (LAD) and LCX arise by a common origin from the left coronary sinus. $\mathbf{d}$ Coronal image showing double SVC 

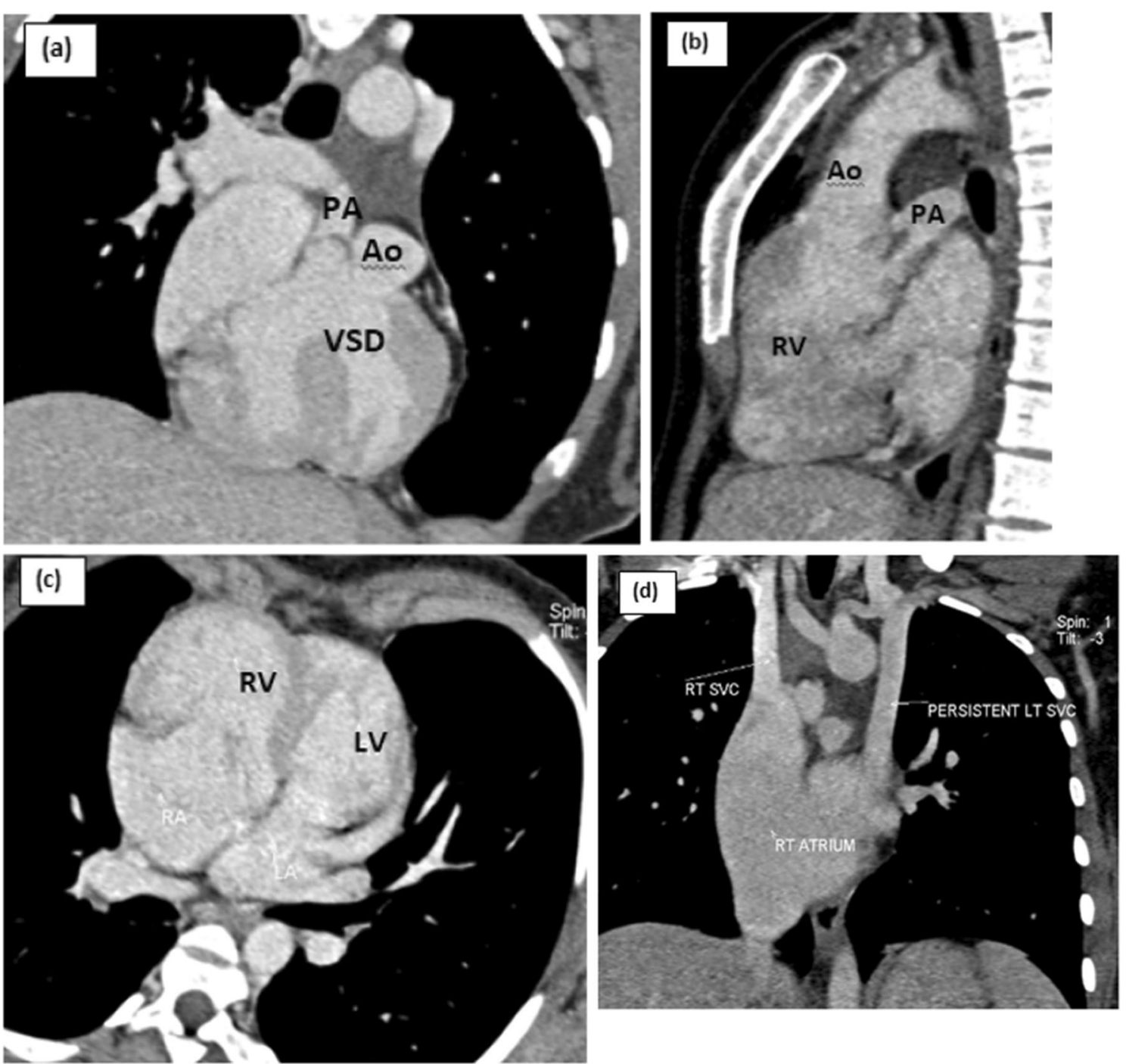

Fig. 5 MDCT. showing: $\mathbf{a}$ and $\mathbf{b}$ aorta and pulmonary artery arising from the right ventricle with VSD seen committed to both aorta and pulmonary artery and thickening of the pulmonary valve is also noted, $\mathbf{c}$ axial image showing Midline location of the heart. $\mathbf{d}$ Coronal image showing double SVC

\section{Discussion}

Double-outlet right ventricle (DORV) defines malformation in which $>50 \%$ of each semilunar valve arises from the morphologic right ventricle (RV) (5). The relationship between the ventricular septal defect and the outflow tracts is particularly important and provides a basis for the classification of cases of DORV [12].

Proper understanding of the relationship between the great vessels and the VSD to the outlets as well as the associated malformations is crucial for proper management and prognosis assessment, raising the surviving rate into adulthood [5-8].

According to our knowledge few papers in literature discussed the DORV anomalies and its associations may be due to the rarity of the disease as it represents $1 \%$ of the congenital heart disease (2).

In the current study the most common clinical type found was Fallot type which represented $48 \%$ of the patients, and it was associated with RVOTO and different types of pulmonary artery anomalies. This was agreed with the study done by Barmou et al. [13], as they reported in their study that the most common type of DORV is Fallot-Type, with similar lesions seen in Tetralogy of Fallot. The second most common clinical type was Taussig-Bing anomaly which represented $30 \%$ of the patients and the VSD was seen committed to the pulmonary artery. It was commonly associated with different aortic artery anomalies e.g. interrupted aortic 
arch and aortic coarctation. This was in agreement with the study of Priya et al. [4], who stated that the second most common DORV variant is Taussig-Bing anomaly with subpulmonic VSD and this form is physiologically similar to transposition of the great arteries. The AVSD/uni-ventricular type represented $16 \%$ of the patients in the current study, with pulmonary and systemic venous anomalies, heterotaxy syndrome and situs anomalies were commonly associated. This observation was also similar to the study done by Pryia et al. [4], mentioned that partial anomalous pulmonary venous connection (PAPVC) and total anomalous pulmonary venous connection (TAPVC) were commonly seen in this variant of DORV, with right and left atrial isomerism were associated respectively. Only three cases with doubly committed VSD and no PS (VSD type), represented only $6 \%$ of the patients. Spaeth et al. [2], reported in their study that doubly committed VSD was seen in $<10 \%$ of patients.

Right ventricular outflow tract obstruction was seen in 24 patients and a total of 16 different pulmonary arteries anomalies and 4 aortopulmonary collaterals were detected mostly in the Fallot type of DORV. Also, twenty aortic anomalies (with the most common of them was right sided aortic arch) were detected commonly in the Fallot type. However, interrupted aortic arch, aortic coarctation and pseudo-coarctation were detected in the Taussig Bing anomaly "Subpulmonic-VSD type" due to decreased aortic blood flow. Similar findings were observed in the study of Luo et al. [14], who mentioned that $50 \%$ of the patients with Taussig-Bing anomaly had aortic obstruction. Only six coronary arteries anomalies (CCAs) were detected in our study (12\% of the patients) and this was lower than the study done by Yu et al. [15], stated that the prevalence of CCAs in DORV was approximately $21.43 \%$. This mis-agreement is probably due to smaller sample size in our study.

The diagnostic value of transthoracic echocardiography and MDCT was compared to surgical results in 20 patients who performed surgical interventions, where a total of 53 malformations apart from DORV were found in those patients.

MDCT detected the different great vessels and situs anomalies in those patients with $98.6 \%$ sensitivity, $100 \%$ specificity and $99.5 \%$ accuracy, while TTE missed detecting two pulmonary artery anomalies $(2 / 8)$, one aortopulmonary collateral vessel $(1 / 3)$, one anomalous pulmonary venous connection $(1 / 2)$, one aortic anomaly $(1 / 8)$, and two systemic venous anomalies (2/9), showing a sensitivity, specificity and accuracy of $84.1 \%, 100 \%$ and $96 \%$ respectively.

Our results were in agreement with two other studies, Harraz et al. [16] and Soleimantabar et al. [17]. Harraz et al. [16], reported that MDCT was accurate in revealing pulmonary artery anomalies with 96\% sensitivity, 100\% specificity, $98 \%$ accuracy, $100 \%$ positive predictive value. In 2019, Soleimantabar et al. [17], stated that the sensitivity and specificity of TTE in the diagnosis of aortic arch anomalies was 59\% and 100\% respectively in comparison with CT angiography. In addition, the agreement between the two methods (kappa) in the diagnosis of aortic arch anomalies was 0.72 .

On the other hand, in our study TTE was superior to MDCT for detection of intracardiac anomalies with $100 \%$ sensitivity and $100 \%$ accuracy compared to $87.5 \%$ and $95 \%$ respectively in multi-slice CT and this was concordant with the results of Shi et al. [10], as they mentioned that MDCT appears to be slightly inferior than TTE for the detection of intracardiac anomalies (sensitivity: DSCT, $91.30 \%$; TTE, 100\%). They assumed that multidetector computed tomography missed several tiny anomalies and the reason was that MDCT imaging is a digital-based technology that requires a workstation to convert digital information to gray-scale images; thus, some intracardiac details are too tiny to be demonstrated with certainty.

\section{Limitations of this study}

A relatively small sample size limits the expansion of these results to larger groups. Also, MDCT is unable to evaluate cardiac function which is an important factor for the evaluation of the patients' condition specially that of the right ventricle. MRI could be the modality of choice for detection of both anatomical and functional information. Actually, it is the current gold standard for assessment of right ventricular volumes and function. Also, as the degree of RVOT stenosis is an important prognostic factor in those patients we recommend further studies evaluating it, either through planimetry of the stenotic area or by measuring the pressure gradient using MRI.

\section{Conclusions}

MDCT serves as a rapid, noninvasive imaging modality with good spatial resolution and provides excellent diagnostic image quality and has satisfactory diagnostic accuracy in the preoperative assessment of DORV. In addition, it provides a comprehensive mapping of the anatomy of the associated complex anomalies especially that of extra-cardiac structures such as aorta, systemic veins, pulmonary veins, and pulmonary arteries, which is important for planning in the surgical repair.

However, it can miss intracardiac malformations. So combining the results of MDCT and echocardiography 
would be beneficial to guarantee the accuracy in diagnosis of DORV and associated anomalies.

\begin{abstract}
Abbreviations
DORV: Double-outlet right ventricle; ECG: Electrocardiography; MDCT: Multidetector computed tomography; TTE: Transthoracic echocardiography; VSD: Ventricular septal defect; AVSD: Atrio-ventricular septal defect; ROI: Region of interest; MPR: Multiplanar reformation; MIP: Maximum intensity projection;VR: Volume rendering; MPA: Main pulmonary artery; RP: Right posterior; RA: Right anterior; LA: Left anterior; RVOTO: Right ventricular outflow tract obstruction; CCAs: Coronary arteries anomalies; PAPVC: Partial anomalous pulmonary
\end{abstract} venous connection; TAPVC: Total anomalous pulmonary venous connection.

\section{Acknowledgements}

Not applicable.

\section{Authors' contributions}

Samira Saraya (SS), Yousra Gwaily (YG), Ragab Hani Donkol (RHD), Hazem Hamed Soliman (HHS), Reem Ibrahim Ismail (RII), Mahmoud Saraya (MS) and Eman Hamdy Ibrahim (EHI) contributed to this work. RHD and SS designed research. RII, MS, YG and SS performed research; HHS, SS, YG, MS, RII and EHI analyzed data; HHS, SS, EHI, MS wrote the paper. All authors have read and approved the manuscript.

\section{Funding}

The study has no funding from any resource.

\section{Availability of data and materials}

The datasets used and/or analyzed during the current study are available from the corresponding author on reasonable request.

\section{Declarations}

\section{Ethics approval and consent to participate}

This study was approved by the research ethic committee of the Radiology department of the Faculty of medicine at Cairo University on 11/09/2018; Reference number of approval: 1016-2018. All patients included in this study gave a written informed consent to participate in this research. If the patient was less than 16 years old or unconscious at the time of the study, written informed consent for their participation was given by their parent or legal guardian.

\section{Consent for publication}

All patients included in this study gave a written informed consent to publish the data contained within this study. If the patient was less than 16 years old or unconscious at the time of the study, written informed consent for publication was given by their parent or legal guardian.

\section{Competing interests}

The authors declare that they have no competing interests.

\section{Author details}

'Diagnostic and Intervention Radiology Department, Kasr Al-Ainy, Faculty of Medicine, Cairo University, El-Manial, Cairo 11956, Egypt. ${ }^{2}$ National Heart Institute, Cairo, Egypt. ${ }^{3}$ Pediatrics Department, Faculty of Medicine, Cairo University, Cairo, Egypt. ${ }^{4}$ Cardiology Department, Kasr Al-Ainy, Faculty of Medicine, Cairo University, Cairo, Egypt.

Received: 13 August 2021 Accepted: 9 December 2021

Published online: 04 January 2022

\section{References}

1. Pang KJ, Meng H, Hu SS, Wang H, Hsi D, Hua ZD, Pan XB, Li SJ (2017) Echocardiographic classification and surgical approaches to double-outlet right ventricle for great arteries arising almost exclusively from the right ventricle. Texas Heart Inst J 44(4):245-251
2. Spaeth JP. Perioperative management of DORV. In: Seminars in cardiothoracic and vascular anesthesia, 2014, September. vol. 18, no. 3, pp. 281-289. SAGE Publications, Los Angeles.

3. Lopez CL, Alboliras ET, Hijazi ZM, Hagler DJ (2018) Visual guide to neonatal cardiology. Wiley, Hoboken. https://doi.org/10.1002/9781118635520. ch54

4. Priya S, Nagpal P, Sharma A, Pandey NN, Jagia P (2019) Imaging spectrum of double-outlet right ventricle on multislice computed tomography. J Thoracic Imaging 34(5):W89-W99

5. Boutsikou M, Silveira-Correa A, Kempny A, Grubler M, Piatek P, AlonsoGonzalez R, Swan L, Uebing A, Gatzoulis MA, Dimopoulos K (2016) Double Outlet right ventricle in the adult: a broad spectrum of anatomic diagnoses and their association with arrhythmia and sudden death. Circulation 134:A18479

6. Kumar P, Bhatia M (2021) Role of computed tomography in pre-and postoperative evaluation of a double-outlet right ventricle. J Cardiovasc Imaging 29(3):205

7. Park IS, Goo HW (2019) Double outlet right ventricle (DORV). In: Park IS (ed) An illustrated guide to congenital heart disease. Springer, Singapore, pp 339-355

8. Ntsinjana HN, Hughes ML, Taylor AM (2011) The role of cardiovascular magnetic resonance in pediatric congenital heart disease. J Cardiovasc Magn Resonance 13(1):51

9. Tangcharoen T, Bell A, Hegde S, Hussain T, Beerbaum P, Schaeffter T (2011) Detection of coronary artery anomalies in infants and young children with congenital heart disease by using MR imaging. Radiology 259:240-247. https://doi.org/10.1148/radiol.10100828 (PMID: 21325034)

10. Shi K, Yang ZG, Chen J, Zhang G, Xu HY, Guo YK (2015) Assessment of double outlet right ventricle associated with multiple malformations in pediatric patients using retrospective ECG-gated dual-source computed tomography. PLoS ONE 10(6):e0130987-e130991

11. Rajiah P, Saboo SS, Abbara S (2017) Role of CT in congenital heart disease. Curr Treat Options Cardiovasc Med 19(1):6

12. Frank L, Dillman JR, Parish V, Mueller GC, Kazerooni EA, Bell A, Attili AK (2010) Cardiovascular MR imaging of conotruncal anomalies. Radiographics 30(4):1069-1094

13. Barmou AC, Pop M, Suciu H, Muntean I (2020) Anatomical and vascular anomalies complicating the course of double outlet right ventricle in an infant. Acta Medica Transilvanica 25(2):36-38

14. Luo K, Zheng J, Wang S, Zhu Z, Gao B, Xu Z, Liu J (2017) Single-stage correction for Taussig-Bing anomaly associated with aortic arch obstruction. Pediatric Cardiol 38(8):1548-1555

15. Yu FF, Lu B, Gao Y, Hou ZH, Schoepf UJ, Spearman JV, Cao HL, Sun ML, Jiang SL (2013) Congenital anomalies of coronary arteries in complex congenital heart disease: diagnosis and analysis with dual-source CT. J Cardiovasc Comput Tomogr 7(6):383-390

16. Harraz MM, Abouissa AH, Saleh HA, Attas KA, Al-Yamani SM, Alsulami G, Refai MM (2019) MDCT angiographic findings of various congenital pulmonary artery anomalies in pediatric patients. Egypt J Radiol Nucl Med 50(1):94

17. Soleimantabar H, Sabouri S, Khedmat L, Salajeghe S, Memari B, Ghahderijani BH (2019) Assessment of CT angiographic findings in comparison with echocardiography findings of chest among patients with aortic arch anomalies. Monaldi Arch Chest Disease 89:6

\section{Publisher's Note}

Springer Nature remains neutral with regard to jurisdictional claims in published maps and institutional affiliations. 